\title{
EQUILÍBRIO POSTURAL EM PRATICANTES DE CROSSFIT E PESSOAS INSUFICIENTEMENTE ATIVAS
}

Allan Felipe Mendes da Silva, André Felipe Veronez Paixão e Eros de Oliveira Junior

Centro de Pesquisa em Ciências da Saúde - Universidade Norte do ParanáUNOPAR, Londrina-PR, Brasil

e-mail: silvaallanmendes@hotmail.com

Acesso DOI: http://dx.doi.org/10.34059/ciejop.2019v27i1-19

Introdução: O equilíbrio postural é uma das capacidades físicas mais importantes para a prática do CrossFit, tendo em vista que o método utiliza movimentos funcionais com estímulos constantemente variados. O objetivo deste estudo é comparar o equilíbrio postural estático entre praticantes de CrossFit e pessoas insuficientemente ativas. Metodologia: Fizeram parte deste estudo 20 participantes do sexo masculino, sendo 10 praticantes de CrossFit (grupo CFT) e 10 pessoas insuficientemente ativas (grupo controle-CTL). A avaliação do equilíbrio foi realizada sobre a plataforma de força BIOMEC400 em apoio bipodal e unipodal com os olhos abertos e fechados. Foram utilizados os seguintes parâmetros de equilíbrio baseados no centro de pressão (COP): área de elipse do COP $\left(\mathrm{cm}^{2}\right)$ e velocidade média de oscilações do COP (cm/s) nas direções de movimento anteroposterior (AP) e médiolateral (ML). Resultados: Em ambos os grupos o teste de equilíbrio com os olhos abertos mostrou melhores resultados em relação aos olhos fechados, tanto em apoio bipodal como unipodal. Quando comparados os grupos no teste de equilíbrio em apoio bipodal, o grupo CFT mostrou ser menos performante para a variável velocidade $A P$ e $M L$ com os olhos abertos (AP: CFT=1,29; $C T L=0,71$ e $M L$ : CFT=1,25; $C T L=0,53$ ) e fechados (AP: $C F T=1,36 ; C T L=0,88$ e $M L: C F T=1,26$; $\mathrm{CTL}=0,55)$. No teste de equilíbrio em apoio unipodal, o grupo CFT obteve melhores resultados para a área do COP com olhos abertos (CFT=7,79; $C T L=11,11)$ e fechados ( $C F T=23,78$; $C T L=87,34)$ e para a velocidade $M L$ com olhos fechados ( $C F T=5,54 ; C T L=7,63)$. Conclusão. As estratégias sensoriomotoras de equilíbrio com base no sistema visual proporcionam melhor equilíbrio postural estático em comparação a ausência da visão. No teste de equilíbrio postural em apoio unipodal o grupo praticante de CrossFit obteve melhores resultados quando comparado ao grupo insuficientemente ativo. Em apoio bipodal, o grupo insuficientemente ativo mostrou melhor equilíbrio que o grupo praticante de CrossFit.

Palavras-chave: Equilíbrio postural, CrossFit, Exercício físico 